\title{
A note on the self-reliant horizontal revenue allocation formula
}

\author{
Virtue U. Ekhosuehi ${ }^{1 *}$ \\ ${ }^{1}$ Department of Mathematics, University of Benin, Benin City, Nigeria \\ Received November 22, 2017; Accepted December 30, 2017; Published Online February 8, 2018 \\ Copyright (C) 2017, African Journal of Applied Statistics (AJAS) and The Statistics and \\ Probability African Society (SPAS). All rights reserved
}

\begin{abstract}
Considering the geopolitical tension in the Niger Delta region of Nigeria, a formula which is based on how self-reliant the individual states are, had been proposed for horizontal revenue allocation. The implementation of the formula was aided by a MATLAB program with arbitrary values assigned to the transition parameters. This paper is a research expanded upon in this direction. A test problem is provided by way of simulation to illustrate the utility of the techniques. The paper contributes to the existing literature by devising a way via a linear model to represent the exponential decay in tax revenue and provides a more appropriate MATLAB program 'hra' to aid institutions saddled with the responsibility of revenue allocation in Nigeria on the implementation of the proposed formula for horizontal revenue allocation.
\end{abstract}

Key words: Federation Account, fiscal federalism, horizontal revenue allocation formula, hra program, MATLAB.

AMS 2010 Mathematics Subject Classification : 62P20, $91 \mathrm{~B} 15$.

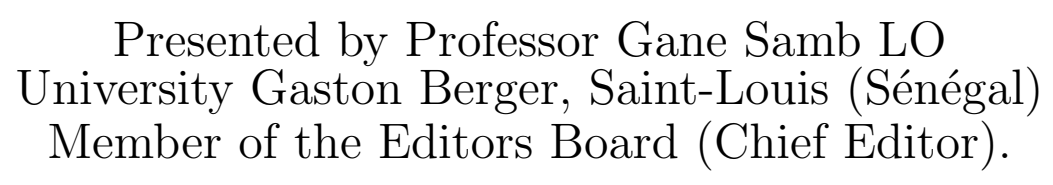

${ }^{*}$ Virtue U. Ekhosuehi: virtue.ekhosuehi@uniben.edu 
Ekhosuehi, V. U., African Journal of Applied Statistics, Vol. 4 (1), 2017, pages 289 - 299. A note on the self-reliant horizontal revenue allocation formula.

Résumé. Dans ce papier nous proposons une formule d'allocation horizontale des revenus entre les états de la Fédération du Nigéria. Cette formule prend en compte la situaton de tension géopolitique dans le delta du Niger au Nigéria et le degré d'autosuffisante interne des états individuels. Par rapport à la littéraure existante, notre contribution se situe dans la mise au point d'une méthode qui, par un modèle linéaire, permet de représenter la décroissance exponentielle des revenus issus des taxes. L'implémentation de la formule a été faite grâce au logiciel MATLAB, à l'aide d'une étude de simulation, avec des valeurs arbitraires données aux paramètres de transition. De cette simulation, nous concluons que nous avons obtenu une méthode appropriée au problème posé, déjà implémentée dans MATLAB. Les techniques dévéloppées sont proposées aux responsables en charge des questions d'allocation afin de les tester avec les paramètres adéquats et de les implémenter au besoin.

\section{Introduction}

The distribution of national revenue from the Federation Account among the various governments in a federation so as to reflect the fiscal responsibilities vested in the central and lower-level governments is referred to as 'revenue allocation'. The subject of revenue allocation in Nigeria has received a considerable attention in the literature (for example, Phillips (1991); Anyanwu (1997); Ekhosuehi and Osagiede (2012)). These studies have shown that the major source of revenue to the Federation Account comes from the export of oil, which is mainly extracted from the oil rich Niger Delta region, and that revenue allocation in Nigeria is a long-standing controversy among the federating units of the intergovernmental sharing scheme and a subject of geopolitical tension.

How to establish a generally acceptable revenue allocation formula is a national question. Attempts have been made in the past to answer this question. But these attempts have been very well criticised owing to the use of derivation as a vertical revenue allocation criterion and population, which is deeply reinforced by political considerations, in the horizontal revenue sharing scheme (Anyanwu (1997); Phillips (1991)). Anyanwu (1997) had given a chronicle of horizontal revenue allocation in Nigeria. At the time of writing this paper, the criteria used for horizontal revenue allocation among the states in Nigeria are based on: minimum responsibilities of government, population, social development factor (e.g., education, health, water, etc.), landmass and terrain, and internal revenue effort. The criterion minimum responsibility of government is the share of revenue to states on the basis of equity. This share is determined by the Revenue Mobilization, Allocation and Fiscal Commission (RMAFC), and it is $40 \%$ of the allocation to states from the vertical revenue sharing scheme. Lukpata (2013) reviewed the politics of revenue allocation in Nigeria and concluded that Nigeria is in a continuous search for a generally acceptable formula for revenue allocation, which super cedes individual or primordial interests. In the same light Umoru (2015) posited that the current revenue sharing formula is archaic and that a new and acceptable revenue sharing formula is needed for the Nigerian state.

Derivation, which is classified as part of special funds in the vertical revenue allocation scheme, has raised a number of controversial views among Nigerians (Anyanwu (1997)). This controversy has led to several separatist agitations. In the oil rich Niger Delta area

Journal home page: www.jafristatap.net 
Ekhosuehi, V. U., African Journal of Applied Statistics, Vol. 4 (1), 2017, pages 289 - 299. A note on the self-reliant horizontal revenue allocation formula.

for example, agitators such as the late Ken Saro-Wiwa and the group Movement for the Survival of Ogoni People (MOSOP) as well as militant groups like the Movement for the Emancipation of Niger Delta (MEND), have expressed their disillusionment and marginalisation occasioned by the revenue allocation formula. To a certain extent derivation should be used to compensate those areas which account for the bulk of the revenues accruing into the Federation Account given the externalities suffered by the inhabitants such as pollution, health hazards, and disruption of socio-economic life of the communities.

Apart from derivation, there is yet another issue which is the use of population as a horizontal revenue allocation criterion. According to Anyanwu (1997) this issue is controversial because there has been no time since the 1960s, where an acceptable census figure was established in Nigeria owing to the politicisation of census figures. Another source of conflict in the intergovernmental revenue sharing scheme is the desire by each state to maximise the application of the criteria which favour its specific peculiarities. At the moment, the country is in a quagmire due to the fluctuation in the global oil price (as oil revenue is a major source of revenue accruing into the Federation Account (Ekhosuehi and Oyegue (2015); Orubu (2002)). One way out of this problem is to diversify the economy so as to boost the revenue from export. But this is not going to be easy in consideration of the level of infrastructure in the country. Another way out of this problem is to encourage the states to be self-reliant by improving their internally generated revenue. This second option of self-reliance was used by Ekhosuehi and Osagiede (2012) to develop a formula for the horizontal revenue sharing scheme.

This study design is centred on parameter estimation and programming with MATLAB. The study aims to provide techniques to estimate the transition parameters and to modify the MATLAB program for the proposed horizontal revenue allocation formula of Ekhosuehi and Osagiede (2012). The MATLAB program is defined by the function hra. 'hra' stands for horizontal revenue allocation. The function hra contains a list of information for horizontal revenue allocation. This function is saved in the MATLAB M-file. The two main features of the function hra are:

1. it uses time series data which comprise: the tax revenue for the states, the number of tax payers, the number of taxable individuals in each state, and the amount budgeted for enforcing tax laws for the states; and

2. it allocates funds to states based on their level of self-reliance.

This study would be of interest to researchers and institutions saddled with the responsibility of revenue allocation in Nigeria such as the Revenue Mobilization, Allocation and Fiscal Commission (RMAFC), the Central Bank of Nigeria (CBN), the Federation Accounts Allocations Committee (FAAC), and the State Joint Local Government Account Committee.

\section{Materials and method}

\subsection{Conceptual framework}

This subsection takes a 'snapshot' into the self-reliant horizontal revenue allocation formula of Ekhosuehi and Osagiede (2012). The formula proposed by Ekhosuehi and Osagiede (2012) is presented as follows. Let $\mu_{i}$ be the maximum tax revenue a state $i$ can collect if

Journal home page: www.jafristatap.net 
Ekhosuehi, V. U., African Journal of Applied Statistics, Vol. 4 (1), 2017, pages 289 - 299. A note on the self-reliant horizontal revenue allocation formula.

there are no anomalies in the tax administration such as tax evasion, $i=1,2, \cdots, N$, with $N$ being the maximum number of states in the federating units. Let $c_{i}(t)$ be the expenditure incurred in enforcing tax laws and in creating awareness on the payment of correct tax by the state $i$. It is assumed that (Ekhosuehi and Osagiede (2012)) the changes in tax revenues with time for the state $i$ is represented by the transition equation

$$
\frac{d x_{i}(t)}{d t}=-\gamma_{i 1} x_{i}(t)+\gamma_{i 2} c_{i}(t)\left[\frac{\mu_{i}-x_{i}(t)}{\mu_{i}}\right], i=1,2, \cdots, N
$$

where $x_{i}(t)$ denotes the tax revenue for state $i, \gamma_{i 1}>0$ is the decay constant associated with losses due to tax evasion and forgetfulness, and $\gamma_{2 i} \in(0,1)$ is the public-fiscal-response constant. Ekhosuehi and Osagiede (2012) arbitrarily assigned values to the parameters $\gamma_{i 1}$ and $\gamma_{i 2}$. The effect of tax evasion and forgetfulness was hypothesised to lead to an exponential decay in tax revenue. That is,

$$
x(t)=x_{0} \exp \left(-\gamma_{i 1} t\right)
$$

where $x_{0}$ represents the tax revenue collected at the beginning of a planning period. Let $W_{-1}^{t_{\text {next }}}$ be the allocation to the state governments in the next fiscal period on the basis of the vertical revenue allocation formula. Then the allocations to states are determined by Ekhosuehi and Osagiede (2012) as

$$
{ }^{i} W_{-1}^{t_{n e x t}}=\left[\xi_{i}+\frac{p}{100 N}\left(1-N \xi_{i}\right)\right] W_{-1}^{t_{n e x t}}
$$

where ${ }^{i} W_{-1}^{t_{n e x t}}$ is the allocation to state $i$ in the next fiscal period, $p$ is the proportion of revenue shared on the basis of equity, $\xi_{i}$ is the relative rank for state $i$ when the discrepancy values, $\delta_{i}=\frac{1}{n} \sum_{i=1}^{n}\left|x_{i}^{*}(t)-x_{i}^{a}(t)\right|$, are arranged in order of magnitude. The discrepancy $\delta_{i}$ is a measure of closeness of the state's independent revenue, $x_{i}^{a}(t)$, to its optimal control path, $x_{i}^{*}(t)$.

The allocation rule $\left[\xi_{i}+\frac{p}{100 N}\left(1-N \xi_{i}\right)\right]$ is the self-reliant formula. This formula was derived from a hybrid of optimal control and utility theories. The closeness of the state's independent (or internally generated) revenue to the optimal control path was used as a proxy for selfreliance. The control problem was solved for a given state, wherein the state independent revenue and the optimum tax revenue are used as points of reference for the variation in the inter-states revenue sharing scheme. Then the Federal Government of Nigeria, which receives utility from how self-reliant the individual states are, rewards the states according to how well the states are doing in relationship to their individual optimal control problems. By this arrangement, the states who are successful in generating the actual tax revenue that is close to the optimum tax revenue will be the ones who receive the highest allocation from the Federation Account. The implementation of the proposed formula in Ekhosuehi and Osagiede (2012) has a limitation owing to the fact that the user needs to assign reasonable values to the transition parameters in the model (for instance, the loss rate in tax revenue and the public-fiscal-response constant) before allocating funds to the state based on how close it is to the optimal control path. The program in Ekhosuehi and Osagiede (2012) was also tailored to a specific example problem for a state regardless of other states in the horizontal level government. This paper is a research expanded upon in this direction.

Journal home page: www.jafristatap.net 
Ekhosuehi, V. U., African Journal of Applied Statistics, Vol. 4 (1), 2017, pages 289 - 299. A note on the self-reliant horizontal revenue allocation formula.

\subsection{Quantitative framework}

In this subsection, a way to estimate the loss rate in tax revenue, $\gamma_{i 1}$, based on the method of least squares is devised using the case of an exponential decay in tax revenue. That is,

$$
x(t)=x_{0} \exp \left(-\gamma_{i 1} t\right)
$$

Suppose data are available in discrete time for $t=1,2, \cdots, n$. Then the exponential function can be transformed to a linear model by taking the natural logarithm of both sides as

$$
\ln x_{i}(t)=\ln x_{0}-\gamma_{i 1} t
$$

Applying the method of least squares (Lindgren (1993)) leads to an estimator of $\gamma_{i 1}$, which is obtained as

$$
\hat{\gamma}_{i 1}=\frac{1}{n \sum_{t=1}^{n} t^{2}-\left[\frac{n(n+1)}{2}\right]^{2}}[0 \quad 1]\left[\begin{array}{cc}
\sum_{t=1}^{n} t^{2} & -\frac{n(n+1)}{2} \\
-\frac{n(n+1)}{2} & n
\end{array}\right]\left[\begin{array}{c}
\ln \prod_{t=1}^{n} x_{i}(t) \\
\sum_{t=1}^{n} t \ln x_{i}(t)
\end{array}\right],
$$

where the hat denotes an estimate.

As a way of estimating the public-fiscal-response constant, $\gamma_{i 2}$, this study assumes a binomial distribution for the number of tax payers with the public-fiscal-response, $\gamma_{i 2}$, as the probability of paying tax. Let $\left(T p_{1}, T p_{2}, \cdots, T p_{n}\right)$ be number of tax payers with $T p_{t}$ being the number of tax payers at $t=1,2, \cdots, n$. Thus population is treated here as the number of tax payers, rather than as the number of people. The distribution of the tax payers at time $t$ is given by

$$
\operatorname{Prob}\left(T p_{t}=p_{t}\right)=\left(\begin{array}{c}
I_{t} \\
p_{t}
\end{array}\right) \gamma_{i 2}^{p_{t}}\left(1-\gamma_{i 2}\right)^{I_{t}-p_{t}}
$$

where $I_{t}$ is the number of taxable individuals at $t=1,2, \cdots, n$. Using the maximum likelihood method on the above expression, we obtain the estimate $\hat{\gamma_{i 2}}$ of $\gamma_{i 2}$ as

$$
\hat{\gamma_{i 2}}=\frac{\sum_{t=1}^{n} p_{t}}{\sum_{t=1}^{n} I_{t}} .
$$

\subsection{The MATLAB program - hra}

In order to make the existing program (Ekhosuehi and Osagiede (2012)) for the horizontal revenue allocation formula more flexible, we write an interactive program for the general problem, and defined it as function hra. The program is implemented in the MATLAB environment. The hra program is given in the appendix. The arguments of hra are data which should be collected over time. These include: the tax revenue, the number of tax payers, the number of taxable individuals, and the amount budgeted for enforcing tax laws. In the program the 'if' construct

if ...

...

else

Journal home page: www.jafristatap.net 
Ekhosuehi, V. U., African Journal of Applied Statistics, Vol. 4 (1), 2017, pages 289 - 299. A note on the self-reliant horizontal revenue allocation formula.

$\cdots$

end

is used to ensure that the loss rate in tax revenue, $\gamma_{i 1}$, is non-negative. The program hra ranks how self-reliant an individual state is compared to the others in the same horizontal level according to the discrepancy (or average absolute deviation). This task is important for the states to know how well they are doing. The number of iterations performed is equal to the number of states in the horizontal level government. The main differences between the program in this paper and that of Ekhosuehi and Osagiede (2012) are the following. The program in this paper is able to accommodate the entire federating units at the same time and computes the relevant parameter values. The function hra does not require any parameter to be arbitrarily assigned a value. Also, the program hra is not tailored to a specific example problem.

The function hra queries the user to enter the following: the percentage share on the basis of equity, which is determined by the commission on revenue allocation, the amount allocated to the states from the vertical revenue allocation scheme and the maximum tax revenue. This information then enables the program to compute at first the optimal tax revenues for the time period and then the average absolute deviation of the optimal tax revenues from the actual tax revenues. The average absolute deviation is used as a means to determine how self-reliant the individual states are. Subsequently, the program rearranges the states according to their delta-magnitude and then returns the share of horizontal revenue to the states in the next fiscal period as well as their allocation for that fiscal period.

\section{Simulation}

To get an insight into the nature and reliability of the MATLAB program, the simulation of observations on the tax revenue as well as the number of tax payers, the number of taxable individuals, and the amount budgeted for enforcing tax laws, is a helpful tool. This is because the application to real life data requires ethical considerations, that is, an approval or permit by both the Board of Internal Revenue and the Ministry of Finance to use such tax information. We illustrate the use of the hra program for the test problem below. The test problem considers a horizontal level government which consists of six federating units with a dataset on the hra inputs for a ten-year period. We randomly generate ten replicates for each argument of hra using the function 'rand' in the MATLAB environment. The MATLAB command 'rand' generates uniform random numbers. The program in the MATLAB environment returns a list of simulated sequence of observations as contained in the hra arguments. The simulated sequence of observations is accessed with

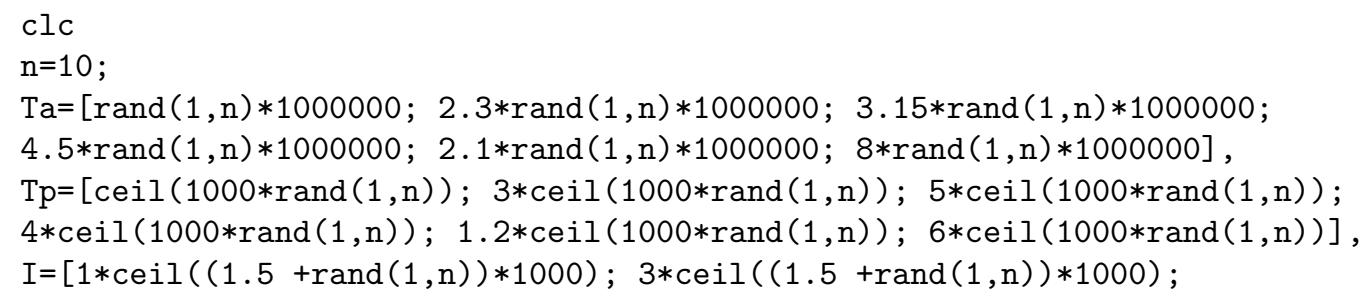

Journal home page: www.jafristatap.net 
Ekhosuehi, V. U., African Journal of Applied Statistics, Vol. 4 (1), 2017, pages 289 - 299. A note on the self-reliant horizontal revenue allocation formula.

$5 * \operatorname{ceil}((1.5+\operatorname{rand}(1, \mathrm{n})) * 1000) ; 4 * \operatorname{ceil}((1.5+\mathrm{rand}(1, \mathrm{n})) * 1000) ; 6 * \operatorname{ceil}((1.5$ $+\operatorname{rand}(1, \mathrm{n})) * 1000) ; 15 * \operatorname{ceil}((1.5+\operatorname{rand}(1, \mathrm{n})) * 1000)]$, $\mathrm{cm}=[\operatorname{rand}(1, \mathrm{n}) * 20000 ; 0.75 * \operatorname{rand}(1, \mathrm{n}) * 20000 ; 5 * \mathrm{rand}(1, \mathrm{n}) * 20000$; $4.2 * r$ and $(1, n) * 20000 ; 6.5 * r$ and $(1, n) * 20000 ; 0.11 * r$ and $(1, n) * 20000]$,

The following results are simulated.

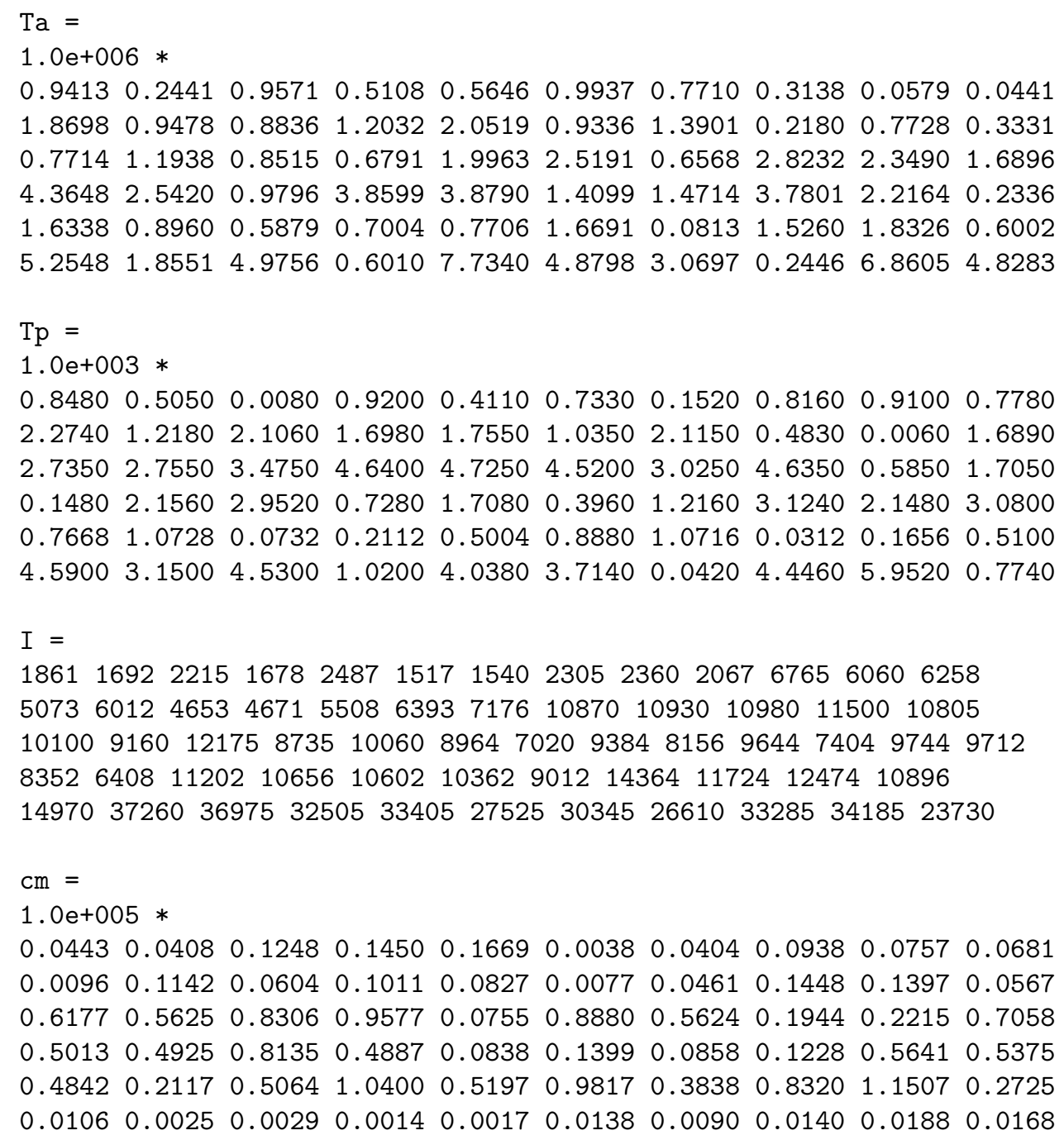

The use of the hra function returns a list of input queries, which the user should supply as it applies to the units being considered as well as the amount available for sharing. The queries are centred on information which is exogenous to the allocation process. For instance, the share on the basis of equity, which is determined by the Revenue Mobilization, Allocation 
Ekhosuehi, V. U., African Journal of Applied Statistics, Vol. 4 (1), 2017, pages 289 - 299. A note on the self-reliant horizontal revenue allocation formula.

and Fiscal Commission (RMAFC) is $40 \%$. Let the amount allocated to the horizontal units from the vertical allocation scheme be 55 million naira. Then assuming that the maximum tax revenue for each of the six units that can be collected during the period is 1100000 , 2300000, 1000000, 5000000, 4200000 and 13000000 (in naira), respectively. Then, we obtain the following.

(i) The decay constants associated with losses due to tax evasion and forgetfulness: $\gamma_{11}=0.2509, \gamma_{21}=0.1473, \gamma_{31}=0, \gamma_{41}=0.1483, \gamma_{51}=0.0298, \gamma_{61}=0.0136$

(ii) The public-fiscal-response constants: $\gamma_{12}=0.0791, \gamma_{22}=0.1961, \gamma_{32}=0.4559, \gamma_{42}=0.2516, \gamma_{52}=0.0808, \gamma_{62}=0.4717$

(iii) The average absolute deviation:

delta $=$

$1.0 \mathrm{e}+006 *$

$\begin{array}{llllll}0.3154 & 0.3956 & 0.7343 & 1.1133 & 0.6024 & 1.9179\end{array}$

(iv) The formula for horizontal revenue allocation, G:

1.00000 .0952

$2.0000 \quad 0.1238$

$5.0000 \quad 0.1524$

$3.0000 \quad 0.1810$

$4.0000 \quad 0.2095$

$6.0000 \quad 0.2381$

(v) The share of horizontal revenue to the states:

state 1: 5238095.24 ; state 2: 6809523.81 ;

state 5: 8380952.38; state 3: 9952380.95 ;

state 4: 11523809.52 ; state $6: 13095238.10$.

Since the results in G are non-negative and sum up to unity, the parameter estimation and the hra program are appropriate for horizontal revenue allocation.

\section{Conclusion}

The function hra is an extension of the MATLAB program in Ekhosuehi and Osagiede (2012) to accommodate the entire horizontal level governments at the same time and then compute the relevant parameter values without any form of arbitrariness of values. We are hopeful that this function would be accepted by the separatist agitators and RMAFC as it is based on the principle of efficiency and as it is far-reaching. Firstly, it proposes that population should be seen as the number of tax payers rather than as the number of people. By so doing, we expect that, if this approach is followed, then states will be more proactive in enforcing tax laws and in engaging in more productive ventures and job creation with a view to increasing the number of tax payers and tax revenues so as to be rewarded more by the Federal Government for their level of self-reliance. This is all the more necessary in view of the dwindling (oil) revenue accruing to the Federation Account as at the time of writing this paper. Thus the allocation formula adopted here settles the controversial issue on the use of population in the revenue allocation criteria. Secondly, this paper contributes to the work of Ekhosuehi and Osagiede (2012) by devising a way to estimate the loss rate in tax revenue and the public-fiscal-response constant. Thirdly, the new MATLAB program hra provides a guide to institutions saddled with the responsibility of revenue allocation in

Journal home page: www.jafristatap.net 
Ekhosuehi, V. U., African Journal of Applied Statistics, Vol. 4 (1), 2017, pages 289 - 299. A note on the self-reliant horizontal revenue allocation formula.

Nigeria on the implementation of the proposed formula for horizontal revenue allocation.

Acknowledgments The author wishes to address his special thanks to the presenter of the paper, for the valuable suggestions, comments and recommendations on the manuscript, which have been used to improve on the version.

\section{References}

Anyanwu, J. C. (1997). Nigerian Public Finance. Onitsha: Joanes Educational Publishers Ltd.

Ekhosuehi, V. U. and Osagiede, A. A. (2012). A proposed formula for horizontal revenue allocation in Nigeria. Asia-Pacific Journal of Operational Research, 29. DOI: $10.1142 /$ S0217595912003746.

Ekhosuehi, V. U. and Oyegue, F. O. (2015). On the state of budgetary balance over time via the one-way classification model. Operations Research and Decisions, 25(3), 5 - 16. DOI: $10.5277 /$ ord150301.

Lindgren, B. W. (1993). Statistical Theory (4th ed.). Chapman \& Hall, New York.

Lukpata, V. I. (2013). Revenue allocation formulae in Nigeria: a continuous search. International Journal of Public Administration and Management Research, 2(1), 32 - 38 .

Orubu, C. O. (2002). The development and contribution of the petroleum industry to the Nigerian economy. In: M. A. Iyoha and C. O. Itsede (Eds), Nigerian Economy: Structure, Growth and Development. Benin City: Mindex Publishing, pp. 31 - 58.

Phillips A. O. (1991). Managing fiscal federalism: Revenue allocation issue. Pulius, 21(4), $103-111$.

Umoru, H. (2015). Existing revenue sharing formula archaic - Senate. Vanguard on $17 / 08 / 2015$.

\section{Appendix}

hra - The new MATLAB program

function hra(Ta, Tp, Ti, cm)

disp(' The Horizontal Revenue Allocation Formula ')

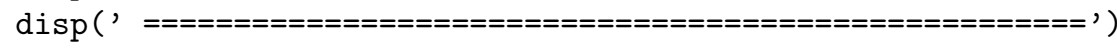

$\%$ Declaration of Data.

$\mathrm{Ta}=\mathrm{Ta}(:,:)^{\prime}$; \% Revenue from taxes in matrix form.

$\mathrm{Tp}=\mathrm{Tp}(:,:) ; \%$ Number of tax payers in matrix form.

$\mathrm{Ti}=\mathrm{Ti}(:,:)$;

$\mathrm{I}=\mathrm{Ti} ; \%$ Number of taxable individuals in matrix form.

Journal home page: www.jafristatap.net 


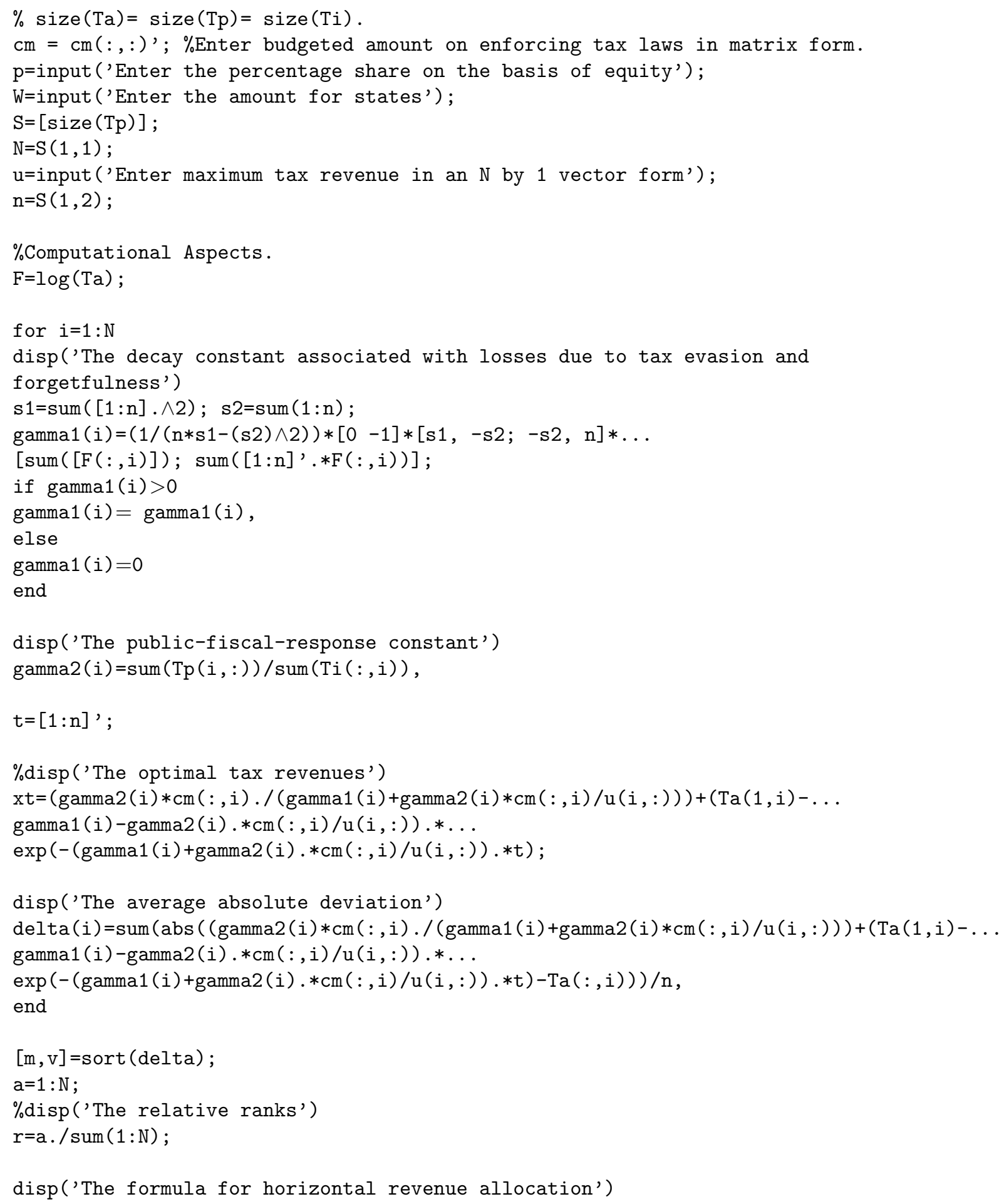


Ekhosuehi, V. U., African Journal of Applied Statistics, Vol. 4 (1), 2017, pages 289 - 299. A note on the self-reliant horizontal revenue allocation formula.

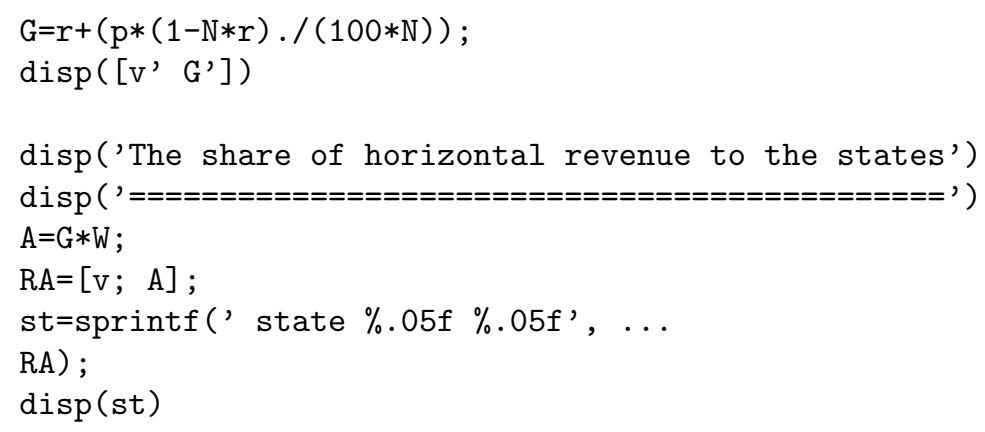

